\section{Agustín Parejo School}

\author{
Centro Andaluz de Arte Contemporáneo, Sevilla
}

Del 30 de enero al 22 de mayo de 2016

\section{Ser parejo}

Siempre recordaré la vez primera que asocié a personas concretas la autoría de aquellas pintadas que inundaron el centro de Málaga a primeros de los años ochenta: «POEZÍA». Eran amigos de un compañero de clase en primer curso de Filología, Miguel Ángel Albarracín, el Mickey, mayores que yo, tampoco tanto, pero con esa distancia que parece insalvable durante los primeros años de tardoadolescencia.

Allí estaban: distantes, exquisitos, absolutely monderniers, gastando gafas de sol durante el desayuno en el Gambrinus que había cerca de la facultad de Letras en San Agustín. Allí estaban Antonio García, Sebas Becerra, la Paqui, Rogelio López Cuenca, Luis, El Moreno, Pedri, Pepe, Maricarmen, Esteban Pujals... Seguro que alguno más, puede que alguno menos aquella vez. Mickey se sentó con ellos. Hablaba con ellos con la familiaridad que daba la pertenencia a un grupo escogido. Eran los más cool. Eran school.

Estaban en otra división. Moreno, que era, y sigue siendo, rubio y de ojos azules, hablaba con un acento imposible como de haber recibido el biberón a lomos de un perro afgano cuando chico. Sebas, siempre con los ojos a punto de salirse de las órbitas, hacía alusiones políticas que me sonaban a chino. Rogelio, cuando se quitaba las gafas de sol, pestañeaba todo el rato. Eran divinos. Pero eran rojos. Tenían una casa en el llano de la Trinidad que compartían todos en comuna. Eran artistas, poetas -yo entonces hacía versos: cuando leí y vi las cosas que hacían sentí una inmediata vergüenza y me cayeron años de antigüedad pasada de moda encima-, se decía que practicaban el amor libre, que lo de uno era de todos y viceversa. El espíritu de la Factory y de Bloomsbury paseaba en mi cateta ciudad. Cada uno venía de un pueblo. Nerja, Alhaurín, Coín, Periana... Yo, que había nacido en París miraba a aquellos hijos del campo con la admiración de quien de pronto ve a un artista de verdad, turbándome entero.

Recuerdo la primera exposición que vi de ellos por aquellas fechas: Por él, cambio. Una coña marinera alrede- dor del líder del PSOE de ese momento, Felipe González, que entonces se vendía -y así lo compramos muchos- con una mezcla de erotismo masculino de morritos ardientes, como el mesías de la rojería. Ellos, que lo habían travestido en los carteles intervenidos de la propia campaña felipista, habían hecho algo que no gozó entonces de mucho predicamento: recordar, por defecto, que el emperador estaba desnudo. EI PSOE arrasó en las elecciones y mis Parejos tocaban las narices. Creo que fue en el Ateneo o en el viejo Museo de Bellas Artes. Ahora me falla la memoria

Poco tiempo después Mickey nos llevó a José Antonio Mesa -amigo de versos desde el instituto, aún poeta, y hoy director del Centro de la Generación del 27- a la casa de la calle Agustín Parejo, en el llano. Recuerdo un cuadro de Oscar Benedí de un tipo tocando el saxo. Libros, libros y más libros. Discos, cuadros, periódicos, revistas, piezas artísticas por todos lados, piezas de diseño. Se contaba que eran unos máquinas robando libros de El Corte Inglés. Mickey, que acabó viviendo en Túnez como corresponsal de EFE y se decía que como confidente -jel espía con la lengua más larga de la Historia!- era de ellos. jÉramos amigos de un Parejo! Ellos fueron mi primera gran impresión y contacto con una modernidad que me parecía imposible en mi ciudad. Hubiera dado un brazo por haber sido un Parejo entonces. Pero ellos estaban, como la mayoría de las mujeres que me gustaban ya entonces, absolutamente fuera de mi alcance.

Recuerdo que la primera semana que llegué a Madrid para enrolarme en un grupo de teatro, serían finales del año 1982 o principios del 83, sentí un estremecimiento singular cuando viendo en la tele de dos cadenas uno de los programas que había que ver entonces, Metrópolis, me encontré a los Parejo en la pantalla. Entonces salir en la tele o ciertos medios no era una cosa tan banal y barata como ahora. Instantáneamente fue como si aquel hecho me otorgara un valor añadido que yo entonces estaba muy lejos de poseer ni de creer siquiera que merecía. Esos que salían en el programa del colmo de lo moderno y yo los conocía. 


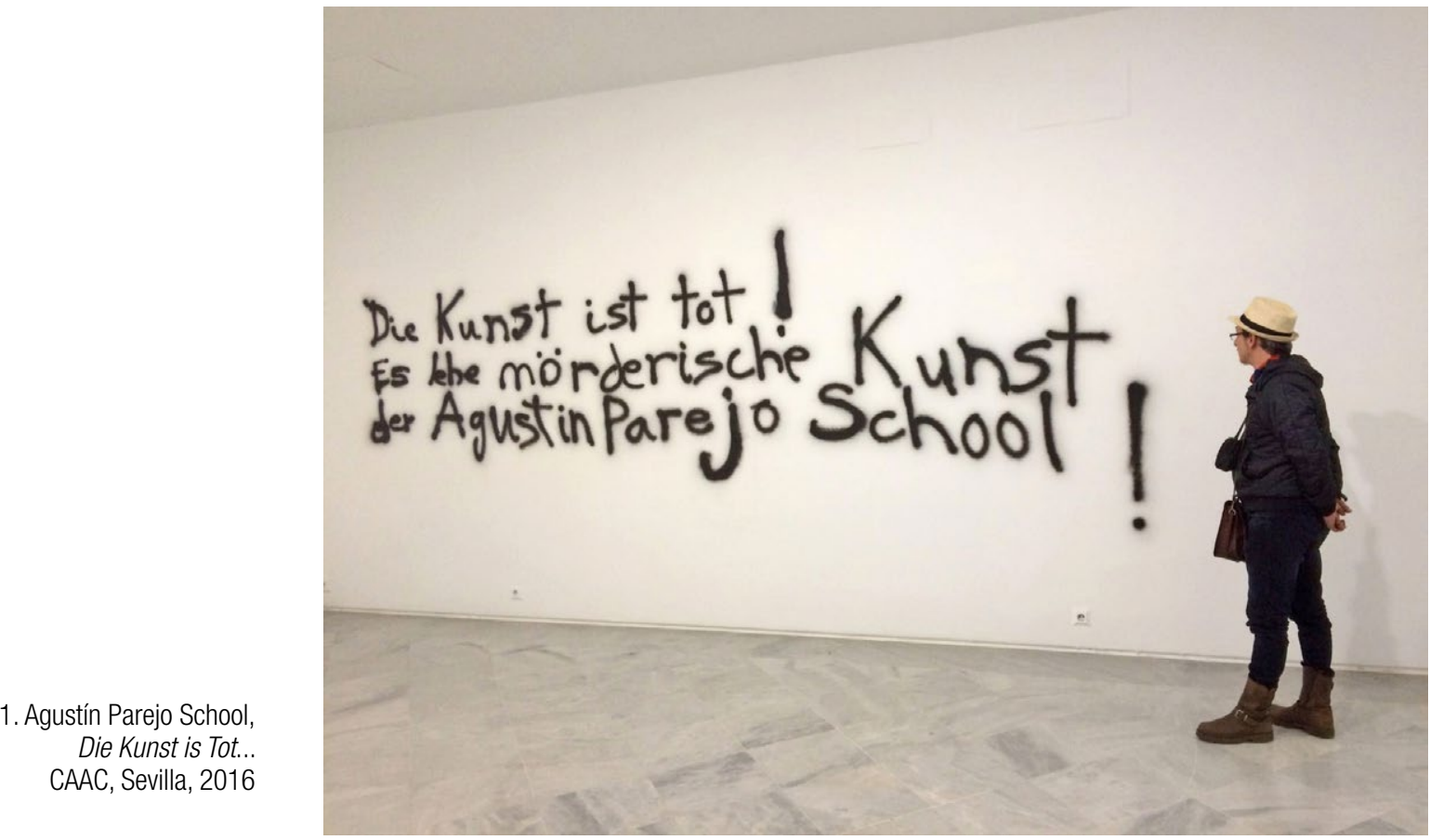

Era amigo de uno de ellos. Ese día me sentí, en la soledad del provinciano de fondo, un poco Parejo. Sí, un usurpador, avergonzado hasta para mí mismo. Pero en esos momentos donde todo estaba cambiando y yo empezaba a lanzarme a la aventura de vivir sin colchón emocional alguno, perdido en la ciudad, uno se agarra a cualquier máscara, a cualquier signo de pertenencia.

No los conocí de verdad, a ellos a su obra y su historia, hasta una década después. Durante todo ese tiempo, como decía, yo había marchado a Madrid a hacer teatro. Había abandonado los estudios de filología que, a pesar de mis intentonas para contentar a mi madre, no quise terminar jamás. Luego había vuelto a Málaga y seguí con el teatro. La poesía cada vez era una actividad más privada y menos creíble para mí. Cuando volvía a Málaga siempre iba a las lecturas de poesía que organizaba la Generación del 27 en calle Ancla, 2, en la plaza de la Marina. Ahora yo vivo en una calle Ancla, 2, pero en otra villa. Un día fui a escuchar a Rogelio López Cuenca con su voz fina y su pestañeo, y su capacidad preclara de aunar referencias e imágenes, conceptos y cosas invisibles fuera donde fuera. Leyó un soneto que era una quiniela. Aluciné con su ingenio, con su dominio del lenguaje. Con la habilidad para deconstruirlo y reventar todas las convenciones artísticas que yo había estudiado como canónicas. Guardaba los números de Puerta Oscura, aquel fotomontaje de una mamada en la que la chorra no eran sino palabras, le poeme, algún cartel arrancado de la calle. Había ido descubriendo a otra gente afín de aquella generación: Justo Navarro, Alfredo Taján, Paco Chica, Tecla Lumbreras y la fantástica programación de los años ochenta del Colegio de Arquitectos...

Al acabar la década entré en un periódico por casualidad. Y ya me hice periodista. Fui acercándome poco a poco a aquellos modernos de Málaga que habían seguido haciendo pintadas, revistas, acciones. Conocí a la madre de mi hijo, también artista. De nuevo aparecieron aquellos tipos que me habían impresionado en mi adolescencia. Los Parejo. Al poco entré a trabajar en el Colegio de Arquitectos. De hecho, quien apostó por mi nombre fue una de las personas que más colaboró con ellos entonces, Ana Tomé. Los fui conociendo personalmente. Trabajé en alguna exposición de ellos divulgándola, Sin Larios. Hice mis primeras acciones filoparejas. Fui a ARCO por primera vez durante el embarazo de mi hijo y allí estaban ellos, en el stand de la galería Carmen de Julián, donde entonces trabajaba también Juanjo Fuentes antes de revelarse como artista. Estudié concienzudamente lo que ha- 


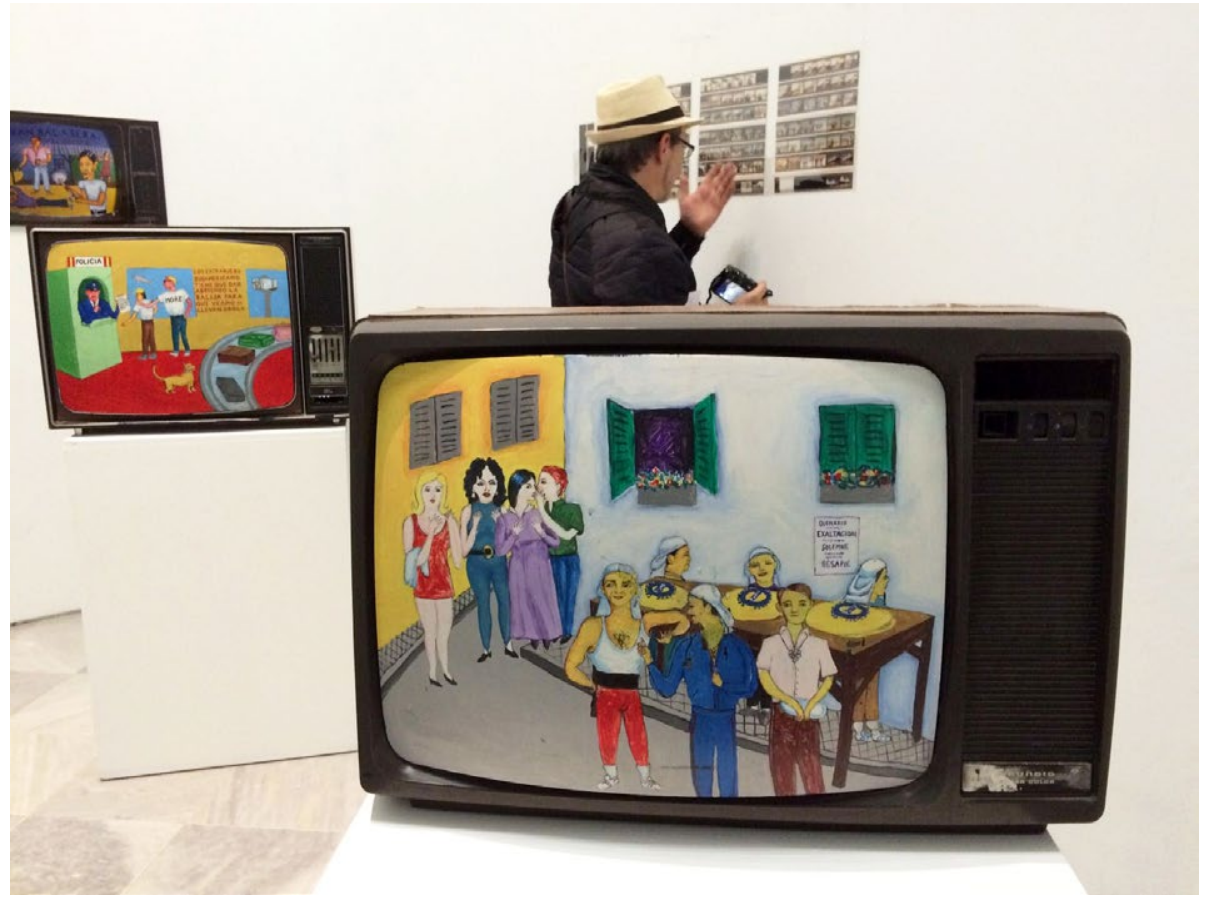

2. Agustín Parejo School, Lenin Cumbe. CAAC, Sevilla, 2016 bían hecho todos esos años donde yo estaba en otra parte pero no dejaba de sonreír cuando veía un pollock pintado en las paredes de mi ciudad aún por restaurar, un Málaga Euskadi Da, colaboraciones en revistas, una edición de Pujals sobre poesía de vanguardia norteamericana...

Ya no tenían la casa del Llano. Ahora tenían un chalé en Coín que era una pasada y que proyectaron con la arquitecta María Eugenia Candau. ¡Ah, la Candau! A la madre de mi hijo, a mi hijo bebé y a mí nos invitaron alguna vez. Rogelio ya trabajaba con Juana de Aizpuru. Habían más Parejos que iban y venían. Ser Parejo seguía siendo lo más. Me hice amigo de muchos de ellos. Ya les entendía y hablaban conmigo. Con algunos he acabado siendo buen amigo. Más de una vez, pasados los años, les hablé de que habría sido muy necesario hacer un documental de aquel grupo irrepetible, fascinante, ese portal estelar hacia otros mundos artísticos, políticos, socioeconómicos, humanos, que no existían en Málaga y sus territorios asociados. Sí, fueron los Parejo y los satélites que se agruparon en su derredor lo más moderno, creativo y revolucionario de la Málaga de al menos dos décadas. Un experiencia única. Aquello debía contarse, ponerse en el lugar que merecían.
Málaga siempre ha sido bastante ignorante de lo que realmente sucede en sus recovecos.

Ahora que hablamos tanto de Bowie, permítaseme la comparación: ellos eran nuestro Bowie colectivo y cambiante. Ser Parejo seguía siendo una aspiración, un premio. Los cotilleos artísticos de aquellos tiempos muchas veces abundaban alrededor de si tal o cual persona era Parejo, asociado, simpatizante o Pata Negra. A veces se les criticaba por su aparente elitismo. Cuando los conocías te desarmaba su hospitalidad. Mucha gente se reivindicaba Parejo sabiendo la carga implícita de categoría y misterio que ello implicaba. Hicieron muchas cosas. Nunca te dejaban indiferente. Apoyaron con su magisterio peculiar a muchísima gente. Tenían amigos hasta en el infierno. Seguían estando más allá de Orión. A veces surgían disputas internas, roces personales que en el runrún del cotilleo artístico malaguita se comentaban como en la peluquería los devaneos de Isabel Preysler o la aristocracia de Alba. Siempre había alguna anécdota descacharrante de Moreno en Nueva York o Mickey en Túnez que seguía acrecentando el mito. La admiración.

Seguramente, esta exposición a la que todo todo bien nacido e interesado en lo que realmente ha sido la histo- 


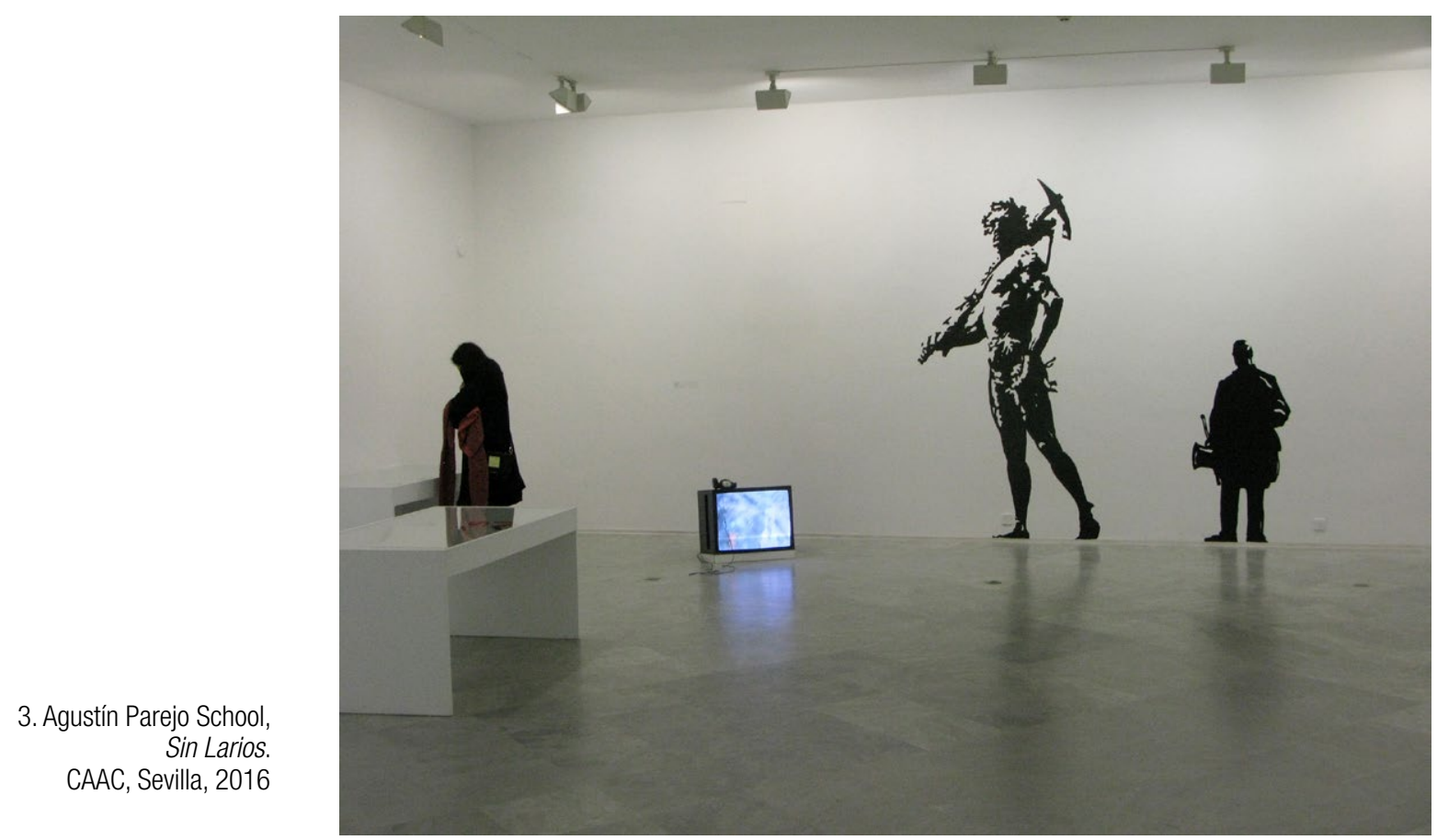

ria de Agustín Parejo School y la del arte contemporáneo en España desde los 80 debería acudir, hará que muchos piensen si llegaron a ser Parejo o no alguna vez durante sus más de treinta años de trayectoria. Yo nunca logré entrar en el Club de la Lucha, lo admito. Pero a mi manera, de la misma manera en la que me gusta mi equipo de fútbol y jamás sería su socio pero disfruto y celebro como propias sus conquistas, yo me siento Parejo. Participo de su espíritu. Ese viernes 29 de enero en Sevilla, todos seremos muy Parejos. Y ser Parejo -sin serlo- es una de las mayores señas de identidad -yo, tan mutante y desclasado- que he sentido en mi vida. "Yo viví y crecí en una ciudad donde se creó la Agustín Parejo School. Fui amigo de muchos de ellos. Tuve ese privilegio».

Felicidades, chicos. Ya era hora.

\section{No estar parejo}

Finalmente, por temas de intendencia, no pude llegar a la inauguración de Los Parejo el 29 de enero. Ya Maite Méndez había leído mi texto espontáneo en Facebook de «Ser Pare- jo» que había gustado bastante, y me dijo si me importaba publicarlo en el Boletín de Arte de la Universidad. Naturalmente, dije. Y luego me fue liando para que hiciera una crítica de la exposición. Así que dos semanas más tarde me fui con mi chica a Sevilla, acogidos por los queridos y también filoparejos Nela y José Ramón, a ver la exposición que había comisariado Jesús Alcaide para el Centro Andaluz de Arte Contemporáneo. Llegué ya de atardecida, un día de viento y lluvia. El espacio estaba bastante vacío y desangelado y comencé a pasear por las salas.

La sensación cuando iba viendo aquella colección de piezas -grabaciones en monitores de televisión; cartelería; documentación y memorabilia varias ocupando vitrinas, audios de la Peña Wagneriana; fragmentos de acciones; algunos de sus lienzos donde la palabra y la política se juntaban; los televisores pintados a la manera del arte popular figurativo africano, sudamericano o criollo del heterónimo Lenin Cumbe, los ejemplares de fanzines, los carteles de la acción Vota Moreno (vota con garbo), que había organizado en su día José María Córdoba en Fuengirola; las sábanas santas numeradas (recordé que yo les había comprado una en su día y la mantenía guardada en su cajita) o las reproducciones 


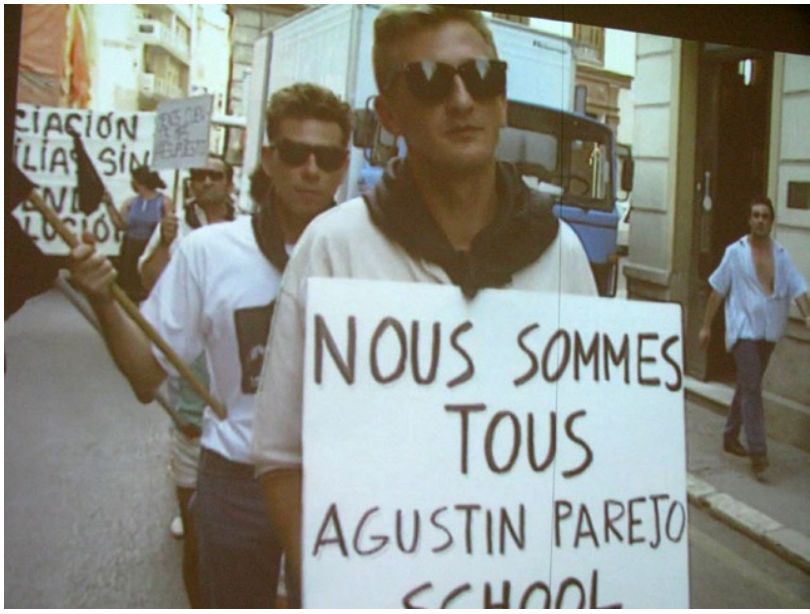

4. Agustín Parejo School, Sin vivienda, CAAC, Sevilla, 2016

de sus pintadas- era de una cierta decepción. Mi compañera, que no conocía en absoluto la historia y acciones de los Parejo, no entendía mucho lo que allí se quería contar. Yo mismo, si no los hubiese conocido, no habría sido capaz de situarme en lo que significaron o hicieron, en el cómo lo hicieron ni en quiénes fueron. A la exposición de los Parejo le faltaba el espíritu Parejo. El humor, la ironía fundamental en sus trabajos sólo brillaba si estaba situada en un contexto: y allí ese contexto o era en exceso débil o brillaba por su ausencia. Yo salí con la sensación de que en aquella exposición no estaba lo Parejo de los Parejo.

Ojo: eso no va en menoscabo del reconocimiento que un trabajo así merece. Sé de buena tinta de las dificultades que para cualquier comisario debe tener recabar información tan dispersa y materiales artísticos y objetos tan nacidos de la nula voluntad de supervivir. El propio espíritu performativo, guarrindongo e irónico de las acciones Parejo, la ausencia -al margen de lo que se consideraba el núcleo duro- de una formación estable y la voluntad de anonimato de un colectivo tan mutante y tan impermeable al Sistema Arte a lo largo del tiempo, es un hándicap bastante insalvable para una labor de documentación de una exposición así. Es por esa razón que siempre creí que cualquier trabajo antológico y crítico sobre su huella debía sustentarse en el terreno del cine documental, precisamente para explicar que tras aquella invisibilidad del individuo en favor del anonimato grupal, se escondían personas concretas con una enorme personalidad y enorme capacidad tanto crítica como estratégica. Gran parte del espíritu Parejo puede observarse y explicarse en el trabajo de Rogelio López Cuenca. Pero es que él comenzó siendo uno de ellos y realmente nunca ha dejado de serlo. RLC llevó al extremo las tesis del grupo y en cualquier análisis histórico y formal de sus estrategias habría que interrelacionar a ambos.

Voy a recordar la exposición/acción Sin Larios, cuya puesta en escena en esta antológica recuerda bastante a la instalación que se hizo en su día en la sala del Colegio de Arquitectos de Málaga, para intentar explicar lo que quiero decir. La acción de los Parejo se encuadraba en un proyecto, Plus Ultra, que Mar Villaespesa comisarió con sendos artistas en cada provincia andaluza. La acción Sin Larios propuesta por los Parejo era la que se pretendía hacer en Málaga: desmontar a la estatua del Marqués de Larios de su pedestal -el marqués de Larios fue el prohombre que desde la burguesía más adinerada tuvo mayor influencia en la ciudad durante el siglo XIX, de hecho la arteria principal de la ciudad se llama así, en su honor- durante un mes, bajarla a pie de calle, ponerla esperando junto al semáforo de enfrente del grupo escultórico y colocar una de las figuras alegóricas que rodean la estatua del marqués durante ese mismo tiempo en su lugar. Y no otra que la alegoría del trabajo, conocida popularmente como «El Mazzantini» porque fue un apolíneo torero de la época, Luis Mazzantini, el que sirvió de modelo a Mariano Benlliure para hacerla en 1896. La propuesta además se sustentaba en un precedente histórico: eso ya había sucedido en las revueltas que tuvieron lugar en Málaga en 1931 cuando el Frente Popular ganó las elecciones. El cartel de la acción recordaba con una fotografía aquel momento republicano en el que el trabajo estuvo en el lugar del capital y la alta burguesía. Bajo la foto del orgulloso Mazantini, lucía el lema «Sin Larios» en el mismo cuerpo y tipo de letra que el de la Gin Larios. Probablemente, pienso ahora, aquella acción hoy se hubiera perdido en el universo de los memes creativos con que el hipsterismo enterado alimenta al Moloch de la redes sociales.

Para cualquier persona inteligente, se trataba de una acción que nunca iba a hacerse. Era más una provocación, un meneo. Y el primero que picó el anzuelo fue el alcalde de Málaga de entonces, el socialista Pedro Aparicio que leyó la acción dentro de un contexto de rencillas políticas y afrentas provinciales entre Málaga y Sevilla. Se indignó, escribió que 
a él nadie le tomaba el pelo, que antes honra sin Expo que Expo'92 sin honra, hizo varias citas de Horacio en latín en las tribunas de la prensa de la ciudad y no dio el permiso. Naturalmente, con todo aquello contaban los Parejo, que lograron un movimiento mediático y un debate durante aquellos días que se saldó con una exposición del proyecto en la sala del Colegio de Arquitectos, la institución que había acogido sus acciones casi desde el inicio de las actividades del grupo en los años ochenta. Todo esto lo recuerdo muy bien porque yo era el encargado de prensa y comunicación del COAM en aquella época. Los dossieres que aparecían en esta muestra del CAAC los había elaborado yo mismo.

Naturalmente, nada de eso se ve y se puede leer en esta muestra donde la ausencia mayor es el contexto, el alma. A estas alturas de cureitorismo ya esperamos que una exposición se cuente por sí misma. Y eso no sucede en la antológica de Agustín Parejo School. Sin embargo para mí y creo que para todos los que se dediquen a la crítica e historiografía de arte contemporáneo en España tiene un valor inmenso. Con el peso que tuvieron los Parejo como grupo seminal en una forma de hacer arte que años después se fue convirtiendo en común en nuestro país no era de recibo que hasta la fecha nadie se hubiera atrevido. Las razones de esa carencia no me corresponde a mí relatarlas aquí. En el caso de la intrahistoria de APS, creo que la evolución de las relaciones personales entre sus fundadores ha tenido no poco que ver en ello. Eso y que, tristemente, los intereses del curadurismo en general tienen más que ver con los ecos mediáticos y las modas que con los vacíos históricos. Como creo que el propio comisario Jesús Alcaide admite, esta exposición es un primer paso. Y como primer paso, a mí me vale de sobra. Eso sí, es necesario recordar que es necesario siempre un contexto para entender la ironía. Las acciones de los Parejo, aunque con referencias y guiños muy cultos por un lado, tenían siempre una lectura popular, una toma e invasión del espacio común. Su re-lectura irónica se basaba en tener en cuenta ambas posiciones. $Y$ sin entendimiento, no hay ironía posible. Es curioso: en las acciones de los Parejo había mucho de arqueología documental, de relectura de las partes ocultas de la Historia por parte del poder para alumbrar sus estrategias. Y Rogelio López Cuenca es tal vez el mejor sampleador de imágenes del arte contemporáneo español para obtener una lectura del sentido esperado. $Y$ esa estrategia de raíces entre bufonescas y anarquistas es el gen absolument Parejo. Ha faltado aquí algún heredero del espíritu Parejo para permitir su relectura treinta y tantos años después.

Al día siguiente, mi compañera y yo lucíamos gripazo de aúpa. Durante la fiebre pensé que el mayor valor de esta muestra es dar el paso siguiente. Ahora falta la gente que quiera seguir portando aquella pancarta: "Nous sommes tous Agustín Parejo School».

Héctor Márquez 